\title{
Inhibition of Inducible Nitric Oxide Synthase, Cycleooxygenase-2 and Lipid Peroxidation by Methanol Extract of Pericarpium Zanthoxyli
}

\author{
Jin-Won Chung, Jin Uk Oh, Sehyung Lee and Sung-Jin Kim* \\ Department of Pharmacology and Toxicology, School of Dentistry, Kyung Hee University, Seoul 130-701, Republic of Korea.
}

*For correspondence: Email: kimsj@khu.ac.kr; Tel: +82-2-961-0868; Fax: +82-2-957-5309.

\begin{abstract}
Purpose: To explore the antioxidant properties of the methanol extract of Pericarpium Zanthoxyli and its effect on inducible nitric oxide synthase (iNOS), cycleooxygenase-2 (COX-2) and lipopolysaccharides (LPS)-induced cell damage in macrophage cells.

Methods: Anti-oxidant activities were tested by measuring free radical scavenging activity (DPPH, NO) and lipid peroxidation levels. The mechanism of anti-oxidant action of Pericarpium Zanthoxyli extract was determined by Western blot analysis for iNOS and COX-2 expression in LPS-stimulated RAW 264.7 cells.

Results: Pericarpium Zanthoxyli extract contained anti-oxidant components including phenolics (2.456 $\mathrm{mg} / \mathrm{g})$, flavonoids $(0.127 \mathrm{mg} / \mathrm{g}$ ) and anthocyanins $(20.34 \mathrm{mg} / \mathrm{g})$. The extract exerted significant radical scavenging activity in a dose-dependent manner. It also inhibited lipid peroxidation and exerted dramatic reducing power (28.9-fold compared with control at a concentration of $1 \mathrm{mg} / \mathrm{ml})$. Production of iNOS induced by LPS was significantly $(p<0.05)$ inhibited by the extract, suggesting that the extract inhibits nitric oxide (NO) production by suppressing iNOS expression. Strikingly, COX-2 induced by LPS was also significantly $(p<0.05)$ inhibited by the extract.

Conclusion: These results suggest that the methanol extract of Pericarpium Zanthoxyli exerts significant anti-oxidant activity via inhibiting free radicals, iNOS and lipid peroxidation as well as by inhibition of COX-2 enzyme.
\end{abstract}

Keywords: Pericarpium Zanthoxyli, Nitric oxide, iNOS, COX-2, Lipid peroxidation, Antioxidant

Tropical Journal of Pharmaceutical Research is indexed by Science Citation Index (SciSearch), Scopus, International Pharmaceutical Abstract, Chemical Abstracts, Embase, Index Copernicus, EBSCO, African Index Medicus, JournalSeek, Journal Citation Reports/Science Edition, Directory of Open Access Journals (DOAJ), African Journal Online, Bioline International, Open-J-Gate and Pharmacy Abstracts

\section{INTRODUCTION}

Pericarpium zanthoxyli refers to the rind of dried fruits of Zanthoxylum bungeanum Maxim., Zanthoxylum schinifolium Sieb. et Zucc., and Zanthoxylum piperitum A. P. DC, which are distributed in Korea and China. It contains a wide variety of components such as (+)-gammacadinene, (+)-beta-pinene, (-)-aromadendrene, ()-isopulegol, (-)-N-acetylanonaine (R-type), hydroxy- $\alpha$-sanshool, hydroxy- $\beta$-sanshool, hydro- xyl-y-sanshool, linalool, nerol, piperitone, skimmianine, terpinen-4-ol, zanthoxylin, zanthobungeanine, $\alpha$-pinene, $(+,-) \alpha$-sanshool, $\alpha-$ terpineol, $\alpha$-thujene, $\beta$-sanshool, $\beta$-sitosterol, $\gamma$ sanshool, trans-ocimene, etc. It has been widely used for cold perspiration in spleen and stomach, cold and painful stomach, diarrhea, chilly waist and knee, indigestion, acute and chronic gastritis, dysentery, toothache, etc, and generally known for antiparasitic and antibacterial effect [13]. Recently, it has been reported that 
Pericarpium zanthoxyli has insecticidal activity [4].

Oxidative stress is caused by imbalance between free radical productions and their scavenging anti-oxidative defense system in the body, leading to damage to cellular components such as lipid, protein and DNA [5]. Most free radicals and their reactive metabolites, such as reactive oxygen species (ROS), are generated by the mitochondrial respiratory chain during cellular metabolism, playing essential roles in cellular signaling pathways. The mitochondrial respiratory chain can also produce nitric oxide (NO) and thus reactive nitrogen species (RNS) [6]. ROS and RNS induce excessive lipid peroxidation, producing other reactive species including malondialdehyde (MDA) and 4hydroxylnonenal (4-HNE) [7].

Antioxidants play crucial roles in preventing lipid peroxidation and removing free radicals. Evidence is mounting that a number of antioxidants such as phenolic acid and flavonoids can reduce the risk of tumors and heart diseases and they are helpful in scavenging ROS which involved in the onsets of those diseases [8]. Inducible nitric oxide synthase (iNOS), is a key enzyme responsible for the production of $\mathrm{NO}$ and it plays an important role in the oxidative stress and inflammation [8]. There are numerous reports that cyclooxygenase-2 (COX-2) is implicated in inflammation via production of various prostaglandins [9].

To explore the anti-oxidant activity of Pericarpium zanthoxyli, the total phenolics, flavonoids and anthocyanin of the methanol extract of Pericarpium zanthoxyli and their in vitro radical scavenging ability were investigated in this study. Furthermore, their effects on the expression of NO, iNOS and COX-2 in lipopolysaccharide (LPS)-stimulated RAW 264.7 macrophage cells were evaluated to understand its mechanism of pharmacological actions.

\section{EXPERIMENTAL}

\section{Preparation of plant extracts}

Dried aerial parts of Zanthoxylum bungeanum Maxim collected in autumn were purchased from Kyung-Dong Oriental Market, Seoul, Republic of Korea. They were authenticated by Professor Emeritus Chang-SooYok, Department of Oriental Pharmacy, Kyung Hee University, Seoul, Republic of Korea. A quantity (100 g) was cut into small pieces and extracted three times with $70 \%$ methanol $(300 \mathrm{ml})$ for $3 \mathrm{~h}$ via sonication.
The resulting methanol extract was concentrated in a rotary evaporator and freeze-dried (FD5510 Freeze Dryer, Ilshin Lab., Republic of Korea).

\section{Measurement of total phenolics}

The total phenolic content (TPC) was determined using the Folin-Ciocalteu reagent with gallic acid as a standard [10]. Basically, $0.5 \mathrm{ml}$ test sample was mixed with $0.5 \mathrm{ml}$ Folin-Ciocalteu reagent and $1.5 \mathrm{ml} 10 \%$ sodium carbonate solution. After the mixture was reacted for $10 \mathrm{~min}$ at $75^{\circ} \mathrm{C}$, the absorbance was read spectrophotometrically (Ultrospec 2000, Pharmacia Biotech, England) at $760 \mathrm{~nm}$. The results were expressed in milligram gallic acid equivalents per gram of dried sample.

\section{Measurement of total flavonoids}

Total flavonoids were measured using the method of Miliauskasa et al [11]. In brief, $200 \mu \mathrm{l}$ test sample was mixed with $200 \mu$ aluminum chloride in ethanol $(20 \mathrm{mg} / \mathrm{ml})$ and the volume was made up to $5 \mathrm{ml}$ with $95 \%$ ethanol. Following incubation for $40 \mathrm{~min}$ at $20{ }^{\circ} \mathrm{C}$, the absorbance of the reaction mixtures was measured spectrophotometrically (Ultrospec 2000, Pharmacia Biotech, England) at a wavelength of $415 \mathrm{~nm}$. Total flavonoid content of the extract was expressed in milligram rutin equivalents per gram of dried sample.

\section{Measurement of total anthocyanins}

The total anthocyanin was measured using a colorimetric assay [12]. Essentially, the extract $(1.0 \mathrm{mg})$ was dissolved in acetate buffer $(25 \mathrm{mM}$, $\mathrm{pH} 4.5,1.0 \mathrm{ml}$ ). Sample absorbence was determined spectrophotometrically (Ultrospec 2000, Pharmacia Biotech, England) at $520 \mathrm{~nm}$ against de-ionized water. Anthocyanin content was expressed as milligrams of kouromanin (cyanidin-3-O-glucoside; KO) equivalents per gram of dried sample.

\section{Measurement of essential oil}

Essential oil contained in the Pericarpium zanthoxyli extract was determined as described in Korean Pharmacopeia [13]. Briefly, the plant extract $(5 \mathrm{~g})$ was dissolved in $50 \mathrm{ml}$ distilled water and subjected to reflux for $5 \mathrm{~h}$; essential oil layer over xylene was measured.

\section{Measurement of total saponin}

The content of total saponin in the Pericarpium zanthoxyli extract was measured as described by Shibata et al [14]. The Pericarpium zanthoxyli extract dissolved in water was extracted with 
ether, and the ether soluble layer was discarded. The resulting water layer was further extracted with saturated butanol. The butanol soluble fraction was collected, evaporated and the residue taken as saponin fraction.

\section{DPPH radical scavenging activity}

Briefly, $1.0 \mathrm{ml}$ of aliquot of extract or control was mixed with $1.0 \mathrm{ml}$ of methanol DPPH $(0.1 \mathrm{mM})$ solution at $23{ }^{\circ} \mathrm{C}$ [15]. After a $30-\mathrm{min}$ reaction, the absorbance was recorded spectrophotometrically (Ultrospec 2000, Pharmacia Biotech, England) at $515 \mathrm{~nm}$. All the experiments were performed in triplicate.

\section{Evaluation of nitric oxide (NO) radical scavenging activity}

NO generated from sodium nitroprusside (SNP) was measured using Griess reagent method [16] whereby $0.5 \mathrm{ml}$ of test sample was added to 0.2 $\mathrm{ml}$ of SNP $(10 \mathrm{mM})$ and $1.8 \mathrm{ml}$ of phosphate buffer $(\mathrm{pH} 7.4)$. The reaction mixture was allowed to incubate at $37^{\circ} \mathrm{C}$ for $3 \mathrm{~h}$. Thereafter, $1.0 \mathrm{ml}$ of the reaction mixture containing nitrite was pipette and mixed with $1.0 \mathrm{ml}$ of Greiss reagent and allowed to stand for $30 \mathrm{~min}$ in diffused light. The absorbance of the pink colored chromospheres was measured spectrophotometrically (Ultrospec 2000, Pharmacia Biotech, England) at $540 \mathrm{~nm}$ against the corresponding blank solution.

\section{Determination of lipid peroxidation (TBARS measurement)}

The final products of polyunsaturated fatty acid oxidation reaction will react with thiobarbituric acid (TBA) to form red floaters. Thiobarbituric acid reactive substances (TBARS) were measured by Sroka's method [17]. TBA reagent was prepared as follows. Reagent A: $375 \mathrm{mg}$ of thiobarbituric acid (Fluka Chemicals) and $30 \mathrm{mg}$ of tannic acid were melted in $30 \mathrm{ml}$ of hot water. Reagent B: $15 \mathrm{~g}$ of thiobarbituric acid was melted into $70 \mathrm{ml}$ of $0.3 \mathrm{M}$ hydrogen chloride solution. Thereafter, $30 \mathrm{ml}$ of reagent $A$ and $70 \mathrm{ml}$ of reagent $B$ were mixed up. Rapeseed oil $(5.2 \mu \mathrm{l})$ was suspended in $2 \mathrm{ml}$ of $0.2 \mathrm{M}$ Tris- $\mathrm{HCl}$ buffer (pH 7.4) containing $15.6 \mathrm{mg}$ of Tween-40. The resulting suspension was irradiated with UV light for $60 \mathrm{~min}$ at $25^{\circ} \mathrm{C}$ and then $100 \mu \mathrm{l}$ of Pericarpium Zanthoxyli extract mixed with $1 \mathrm{ml}$ of the suspension. This mixture was irradiated with UV light for $30 \mathrm{~min}, 2 \mathrm{ml}$ of TBA reagent placed in it, the mixture allowed to react for 15 min over boiling water, and centrifuged for $3 \mathrm{~min}$ at $100 \mathrm{x}$ g. The supernatant was taken and its absorbance measured at $532 \mathrm{~nm}$. Suppression of lipid and oxidation reactions was measured as percentage, compared to the control group not containing Pericarpium zanthoxyli extracts.

\section{Assessment of reducing power}

The reducing power of the extract was measured according to the method of Oyaizu [18]. Test samples in phosphate buffer $(2.5 \mathrm{ml}, 0.2 \mathrm{M}, \mathrm{pH}$ 6.6) was added to postassium ferricyanide (2.5 $\mathrm{ml}, 10 \mathrm{mg} / \mathrm{ml}$ ) solution and the mixture was incubated at $15 \mathrm{~min}$ at $30^{\circ} \mathrm{C}$. Trichloroacetic acid (TCA, $2.5 \mathrm{ml}, 100 \mathrm{mg} / \mathrm{ml}$ ) was added to the mixture, and $2.5 \mathrm{ml}$ of the mixture was mixed with $2.5 \mathrm{ml}$ of distilled water and $0.5 \mathrm{ml}$ of ferric chloride $(1.0 \mathrm{mg} / \mathrm{ml})$. Absorbance was read spectrophotometrically (Ultrospec 2000, Pharmacia Biotech, England) at $700 \mathrm{~nm}$.

\section{Cell culture and measurement of nitric oxide}

$\begin{array}{llll}\text { The murine macrophage, RAW } 264.7 & \end{array}$ (ATCC ${ }^{\circledR}$ TIB-71) cells, were purchased from American Type Culture Collection (ATCC, Manassas, VA, USA) and cultured in Dulbecco's modified essential media (DMEM; Gibco, Invitrogen, Carlsbad, CA, USA) supplemented with $10 \%$ heat-inactivated foetal bovine serum (FBS; Gibco, Invitrogen, Carlsbad, CA, USA), streptomycin $(100 \mu \mathrm{g} / \mathrm{ml})$ and penicillin (100 $\mathrm{U} / \mathrm{ml}$ ) at $37{ }^{\circ} \mathrm{C}$ in a $5 \% \mathrm{CO}_{2}$ atmosphere. Cells were seeded at a density of $2 \times 10^{6}$ onto each well in a 6 -well plate for $24 \mathrm{~h}$ before drug treatment. The cells were incubated with test sample at different concentrations (1.0, 0.1 and $0.01 \mathrm{mg} / \mathrm{ml}$ ). Four hours later, the cells were stimulated with lipopolysaccharides (LPS, 1 $\mu \mathrm{g} / \mathrm{ml}$; Sigma Chemical Co., St. Louis, MO, USA) except for the control group for $20 \mathrm{~h}$. The concentration of $\mathrm{NO}$ in culture supernatants was determined as nitrite, a major stable product of NO, by the Griess reagent assay. The absorbance of the pink colored chromospheres was measured spectrophotometrically (Ultrospec 2000, Pharmacia Biotech, England) at $540 \mathrm{~nm}$ against the corresponding blank solution and results were expressed as $\mathrm{mM}$ nitric oxide.

\section{Western blot analysis}

Cells were washed twice with $1 x$ PBS, scraped off, and centrifuged at 5,000 rpm for 5 min at 4 ${ }^{\circ} \mathrm{C}$. Cell pellets were resuspended in an appropriate volume of lysis buffer containing 10 mM Tris- $\mathrm{HCl}$, pH 7.4, $50 \mathrm{mM} \mathrm{NaCl}, 5$ mM EDTA, $30 \mathrm{mM} \mathrm{NaF}, 0.1 \mathrm{mM} \mathrm{Na}_{3} \mathrm{VO}_{4}, 1 \%$ triton X-100, $0.5 \%$ NP-40, $1 \mu \mathrm{g} / \mathrm{ml}$ leupetin, $1 \mu \mathrm{g} / \mathrm{ml}$ aprotinin and incubated for $30 \mathrm{~min}$ on ice. Lysates were then centrifuged at $12,000 \mathrm{rpm}$ for $10 \mathrm{~min}$ at $4^{\circ} \mathrm{C}$ and the supernatants were used as the total cell lysates. The protein concentration of each 
sample was determined by the Bradford assay (Bio-Rad, CA, USA) [19]. $50 \mu \mathrm{g}$ of protein were separated on $10 \%$ sodium dodecyl sulfate (SDS)-polyacrylamide gels and transferred to nitrocellulose membranes (Schleicher and Schuell, Keene, NH, USA) as described by Towbin et al [20]. Each membrane was incubated for $1 \mathrm{~h}$ with $5 \%$ skimmed milk in $0.1 \mathrm{M}$ Tris-buffered saline-0.1\% Tween 20 (TBS-T) buffer ( $\mathrm{pH}$ 7.4) to block non-specific binding and then incubated with primary antibodies that recognized iNOS $(1: 1000 ;$ Santa Cruz Biotechnology, Santa Cruz, CA, USA), COX-2 (1:2000; Santa Cruz Biotechnology, Santa Cruz, CA, USA) and GAPDH (1:1000; Santa Cruz Biotechnology, Santa Cruz, CA, USA). Each protein was detected by using a chemiluminescence detection system according to the manufacturer's protocol (ECL, Amersham, UK). The band intensity was quantified by $\mathrm{NIH}$ ImageJ densitometric analysis.

\section{Statistical analysis}

Data analysis was carried out using Graphpad Prism 5.0 software, and the data are expressed as mean \pm standard error of mean (SEM). The significance level of treatment effects was determined by one-way analysis of variance (ANOVA) followed by Tukey's post hoc analysis; $p$-values less than 0.05 were considered statistically significant.

\section{RESULTS}

\section{Phytochemical yield}

Amount of total phenolic content in the Pericarpium zanthoxyli was $2.456 \mathrm{mg} / \mathrm{g}$ while the yield of total flavonoids and total anthocyanins was 0.127 and $20.34 \mathrm{mg} / \mathrm{g}$, respectively. In addition, the extract contained 13.7 and $8.0 \%$ of total saponin and essential oil, respectively.

\section{Antioxidant activity}

Fig $1 \mathrm{~A}$ shows the dose-response results of the $\mathrm{DPPH}$ radical scavenging activities of the Pericarpium Zanthoxyli. DPPH radical scavenging ability of the extract at $0.01,0.1$ and $1.0 \mathrm{mg} / \mathrm{ml}$ was 46,89 and $64 \%$, respectively, compared to control. In comparison, vitamin C, used as standard, decreased DPPH radicals by 23,25 and $34 \%$ at concentrations of $0.01 \mathrm{mg} / \mathrm{ml}$, $0.1 \mathrm{mg} / \mathrm{ml}$ and $1.0 \mathrm{mg} / \mathrm{ml}$, respectively. These results suggest that Pericarpium Zanthoxyli possesses hydrogen-donating abilities to act as an antioxidant. Fig $1 \mathrm{~B}$ depicts that at $0.01,0.1$ and $1.0 \mathrm{mg} / \mathrm{ml}$, the Pericarpium Zanthoxyli extract scavenged nitric oxide radicals by 28,35 and $45 \%$, respectively, compared to control. Vitamin $\mathrm{C}$ at concentrations of $0.01,0.1$ and 1 $\mathrm{mg} / \mathrm{ml}$ exerted 22,26 and $52 \%$ decrease of nitric oxide radicals, respectively.
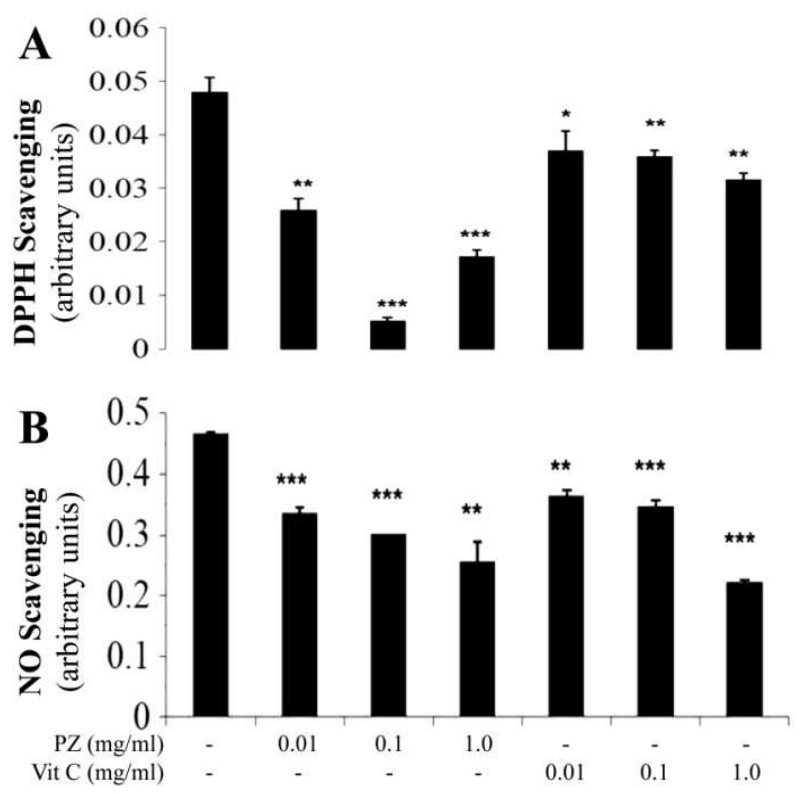

Fig 1: DPPH and NO scavenging activity by the Pericarpium zanthoxyli extract. Data are mean \pm S.E.M $(n=3) ;{ }^{*} p<0.05$ and ${ }^{* *} p<0.01 ;,{ }^{* * *} p<0.001$

Fig 2 shows the antioxidant data for the based on reducing power. The results indicate that the Pericarpium Zanthoxyli extract had reducing power of 2.0-, 6.1- and 28.9-fold at 0.01, 0.1 and $1 \mathrm{mg} / \mathrm{ml}$, respectively, compared to control; for the reference standard, vitamin $\mathrm{C}$, the corresponding values were 1.8-, 2.6- and 4.0fold, respectively.

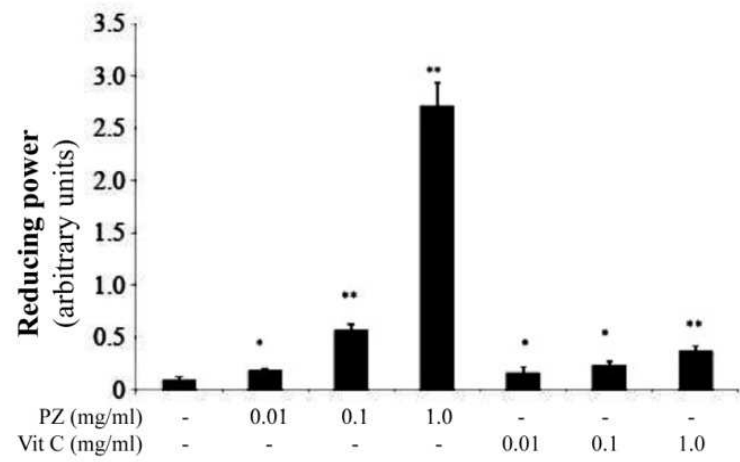

Fig 2: Reducing power by the Pericarpium zanthoxyli extract. Data are mean \pm S.E.M $(n=3) ;{ }^{*} p<0.05$ and ${ }^{* *} p<0.01$

The TBARS production was significantly suppressed by the Pericarpium zanthoxyli extract by 33,34 and $35 \%$ at concentrations of $0.01,0.1$ and $1 \mathrm{mg} / \mathrm{ml}$, respectively, and was largely equivalent to Vitamin $\mathrm{C}$ in activity (Fig 3 ). 


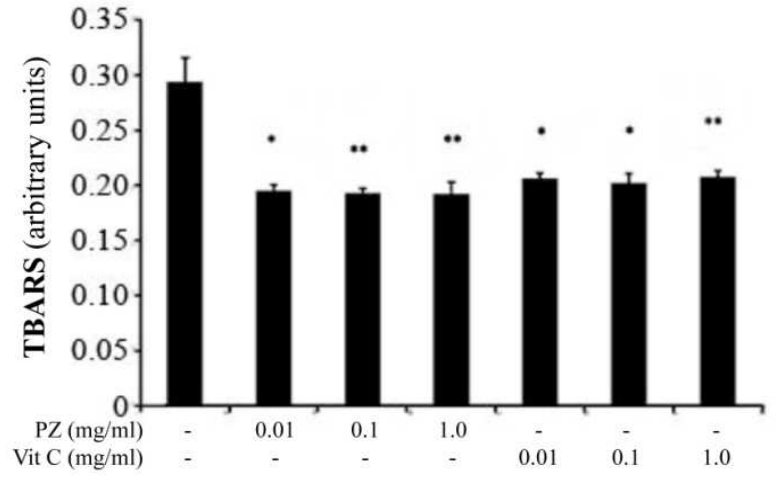

Fig 3: TBARS inhibition by the Pericarpium zanthoxyli. Data are mean \pm S.E.M $(n=3) ;{ }^{*} p<0.05$ and ${ }^{* *} p<$ 0.01

Fig 4 shows that treatment with LPS induced a high release of $\mathrm{NO}$ to the culture medium but pretreatment with Pericarpium zanthoxyli extract resulted in inhibition of NO production by 41,95 and $99 \%$ at concentrations of $0.5,0.1$ and 1.0 $\mathrm{mg} / \mathrm{ml}$, compared to LPS-induced sample.

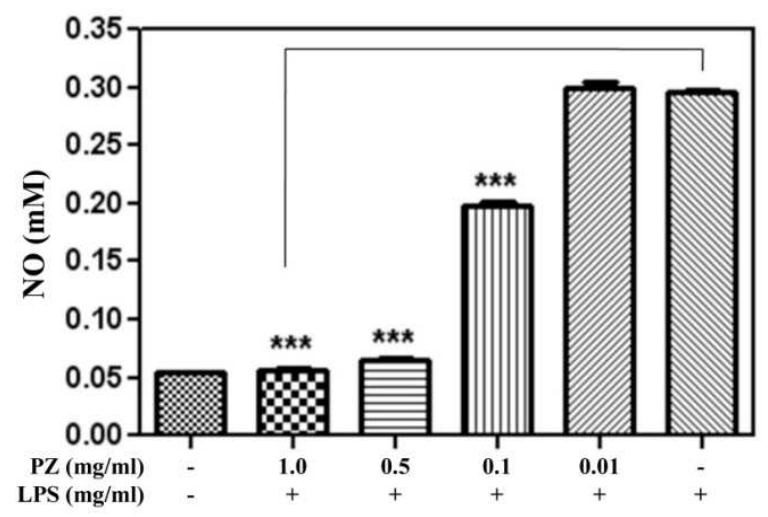

Fig. 4: Inhibition of NO production by the Pericarpium zanthoxyli extract. Data are mean \pm S.E.M $(n=3)$; ${ }^{* * *} p<0.001$.

Fig 5 indicates that protein expressions of iNOS and COX-2 significantly increased (5.9- and 10.5-fold for iNOS and COX-2, respectively) upon LPS treatment in RAW 264.7 cells compared to control. The extract considerably inhibited the expression of LPS-induced iNOS (29, 38 and $100 \%$; Fig. 5A) and COX-2 (33, 19 and $84 \%$; Fig.5B) at $0.10 \mathrm{mg} / \mathrm{ml}, 0.1 \mathrm{mg} / \mathrm{ml}$ and $1 \mathrm{mg} / \mathrm{ml}$, respectively, in RAW 264.7 cells.

\section{DISCUSSION}

Pericarpium zanthoxyli has long been used in oriental medicine for the treatment of various diseases such as pain, inflammation and bacterial infection. In the present study, the antioxidative mechanism of its extract has been explored. We propose that the extract inhibits
iNOS and COX-2 induced by LPS, thereby exerting its anti-oxidant actions.

The present study indicates that the extract contains significant amount of phenolics, including flavonoids and anthocyanins, which are known antioxidant components and have been recognized as having the potential to ameliorate diseases by helping to neutralize free radicals. Various ways are being developed to measure the potential of natural products with various antioxidant mechanisms. DPPH is a stable free radical and has been used extensively to test the ability of natural products to act as free radical scavengers or hydrogen donors [21]. Antioxidants either transfer an electron or a hydrogen atom to DPPH, thus neutralizing a number of DPPH molecules equal to that of hydroxyl groups [22]. In addition to scavenging $\mathrm{DPPH}$, the extract also showed nitric oxide scavenging activity. The toxicity and damage caused by NO with superoxide anion is multiplied as they react to produce reactive peroxynitrite (ONOO-), leading to serious toxic reactions with protein, lipids and nucleic acids [23]. In this study, scavenging of free radicals increased with extract concentration and its activity was greater than that of vitamin $\mathrm{C}$, the reference standard. The NO scavenging activity of the extract may help to arrest the chain reactions initiated by excess generation of ONOO- which is detrimental to human health.
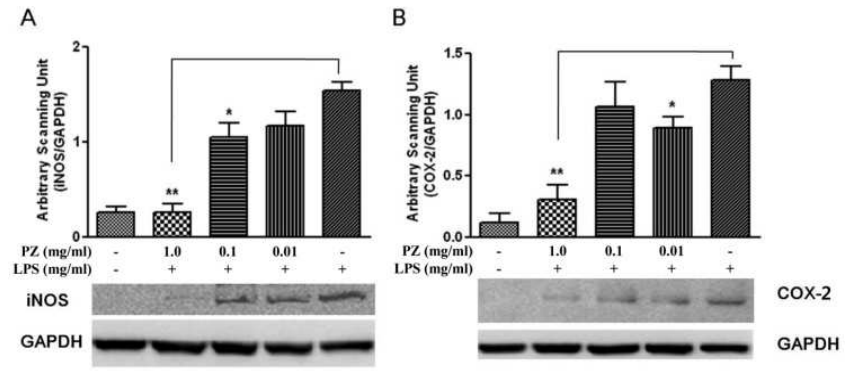

Fig 5: Effect of the Pericarpium zanthoxyli extract on LPS-induced iNOS and COX-2 induction. Data are mean \pm S.E.M $(\mathrm{n}=3) ;{ }^{*} p<0.05$ and ${ }^{* *} p<0.01$

Degree of lipid peroxidation is widely used as an index of oxidative stress and analyzed by measuring thiobarbituric acid reactive substances (TBARS) [24]. Lipid peroxides are unstable and are decomposed into various kinds of compounds including carbonyl compounds. As a group of small molecular weight substances, TBARS represents mainly malonaldehyde and some other compounds such as 4-hydroxy-2nonrenal (HNE) and acrolein. Its reducing ability generally depends on the presence of reductants [25]. The reductants causes the reduction of the $\mathrm{Fe}^{3+}$-ferricyanide complex to the ferrous form by 
donating a hydrogen atom and exhibited antioxidiative potential by breaking free radical chain reactions [26]. Pericarpium zanthoxylis remarkable reducing power could be of great benefit in the prevention and treatment of many diseases caused by oxidative stress. Thus, it cannot only remove various kinds of free radicals generated through oxidative stress but also inhibit the lipid peroxidation triggered by the generation of free radicals. These dual antioxidant actions could be of great value as a potential functional food candidate.

In macrophages, high concentrations of nitric oxide radical can be converted into peroxynitrites, which cause diverse chemical reactions in a biological system including nitration of tyrosine residue of protein, triggering lipid peroxidation, inactivation of aconites, inhibition of mitochondrial electron transport, and oxidation of biological thiol compounds [27]. The findings of the present study strongly suggest that Pericarpium zanthoxyli has the ability to reduce nitric oxide production by LPS in the RAW 264.7 macrophages. Results from Western blotting analysis further indicate that the enzyme, iNOS, is responsible for long-lasting nitric oxide production and it is strikingly induced by LPS as shown in this study. In addition to inhibition of NO release, the extract also significantly inhibited iNOS expression in LPS-stimulated RAW 264.7 macrophages in a dose-dependent manner. Interestingly, COX-2, which is responsible for proinflammatory prostaglandin formation, was increased by LPS and it was also inhibited by extract treatment. These results suggest that the anti-oxidative action of the extract is mediated by the inhibition of both iNOS-NO system and COX2 enzyme.

Reactive oxygen and nitrogen species can be generated as by-products during oxidative processes of living organisms [28]. Many diseases, including aging, cancer, cardiovascular disease, periodontal disease, neurodegenerative disease and inflammation, are linked to excessive amounts of free radicals [29]. In the present study, we provide evidence that Pericarpium zanthoxyli extract exerts remarkable anti-oxidative actions via free radical scavenging activities, inhibition of NO production, iNOS and COX-2 expression and inhibition of lipid peroxidation. The results of the present study indicate that the plant has powerful free radical scavenging capacity which may be due to the presence of phenolics such as flavonoids and anthocyanins.

\section{CONCLUSION}

We propose that the immunomodulatory activity of the Pericarpium zanthoxyli extract depends on the inhibition of NO production and iNOS/COX-2 expression. The anti-oxidative actions of the extract could be useful in preventing and treating many diseases caused by oxidative stress and there can be exploited as an active component of functional foods.

\section{REFERENCES}

1. Cheong, Bo-seop and Shin, Min-gyo, Iconographical Folk Medicine Encyclopedia, Younglim Co., Ltd, 1999; pp 795-796.

2. New Oriental Medicine Handbook, Traditional Oriental Medicine Database, Scientific Research Center of Natural Substances, Seoul University, 1999.

3. Zhang $M$, Chen $Y$, Zhu Z, Chen G. Pharmacological studies on warming the middle-jiao to alleviate pain by PericarpiumZanthoxyli. Zhongguo Zhong Yao Za Zhi. 1991; 16: 493-497.

4. Wang CF, Yang, K, Zhang, HM, Cao J, Fang R, Liu ZL, $D u$, SS, Wang $Y Y$, Deng $Z W$, Zhou $L$. Components and insecticidal activity against the maize weevils of Zanthoxylum schinifolium fruits and leaves. Molecules 2011; 16: 3077-3077.

5. Fridovich I. The biology of oxygen radicals. Science 1978; 201: 875-880.

6. Poyton RO, Ball KA, Castello PR. Mitochondrial generation of free radicals and hypoxic signaling. Trends Endocrinol Metab 2009; 20: 332-340.

7. Hussain SP, Hofseth LJ, Harris CC. Radical causes of cancer. Nat Rev Cancer 2003; 3: 276-285.

8. Conforti F,Menichini F. Phenolic compounds from plants as nitric oxide production inhibitors. Curr Med Chem 2011; 18: 1137-1145.

9. Uchida KA. Lipid-derived endogenous inducer of COX-2: a bridge between inflammation and oxidative stress. Mol Cells 2008; 25: 347-351.

10. Singleton VL, Rossi JA (Jr). Colorimetry of total phenolics with phosphomolybdic-phosphotungstic acid reagents. Am J Enol Vitic 1965; 16: 144-158.

11. Miliauskas G, Venskutonis PR, van Beek TA. Screening of radical scavenging activity of some medicinal and aromatic plant extracts. Food Chem 2004; 85: 231-237.

12. Piccolella S,Fiorentino A,Pacifico S,D'Abrosca B,Uzzo $P$, Monaco $P$. Antioxidant properties of Sour Cherries (Prunuscerasus L.): role of colorless phytochemicals from the methanolic extract of ripe fruits. J Agric Food Chem 2008; 56: 19281935.

13. Shibata S, Ando T, Tanaka O, Meguro Y, Sôma K, lida $Y$. Saponins and sapogenins of Panax ginseng C.A. Meyer and some other Panax spp. Yakugaku Zasshi. 1965;85:753-755.

14. Korean Pharmacooeia, $6^{\text {th }}$ edn, 1992; $p 1323$.

15. Brand-Williams W, Cuvelier ME, Berset $C$. Use of a free radical method to evaluate antioxidant activity. Lebenson Wiss Technol 1995; 28: 25-30.

16. Yen GC, Lai HH, Chou HY. Nitric oxide-scavenging and antioxidant effects ofUraria crinite root. Food Chem 2001; 74: 471-478.

17. Sroka Z, Cisowski W. Hydrogen peroxide scavenging, antioxidant and anti-radicalactivity of some phenolic acids. Food Chem. Toxicol 2003; 41: 753-758.

18. Oyaizu M. Studies on products of browning reactions: antioxidative activities of products of browning 
reaction prepared from glucosamine. Jap J Nutr 1986; 4: 307-315.

19. Bradford MM. A rapid and sensitive method for the quantitation of microgram quantities of protein utilizing the principle of protein-dye binding. Anal Biochem 1976; 72: 248-254.

20. Towbin H, Staehelin T, Gordon J. Electrophoretic transfer of proteins from polyacrylamide gels to nitrocellulose sheets: procedure and some applications. Proc Natl Acad Sci USA 1979; 76. 4350-4354.

21. Liyana-Pathirana CM, Shahidi F. Antioxidant properties of commercial soft and hard winter wheats (Triticumaestivum L.) and their milling fractions. $J$ Sci Food Agric 2006; 86: 477-485.

22. Barros L, Ferreira MJ, Queiros B, Ferreira ICFR, Baptista $P$. Total phenols, ascorbic acid, [beta]-carotene and lycopene in Portuguese wild edible mushrooms and their antioxidant activities. Food Chem 2007; 103: 413-419.

23. Yermilov V, Rubio J,Becchi $M$, Friesen $M D$,Pignatelli $B$, Ohshima $H$. Formation of 8-nitroguanine by the reaction of guanine with peroxynitrite in vitro. Carcinogenesis 1995; 16,: 2045-2050.
24. Selek $S$, Herken $H$, Bulut M, Ceylan MF, Celik $H$, Savas $H A$, Erel O. Oxidative imbalance in obsessive compulsive disorder patients: a total evaluation of oxidant-antioxidant status. Prog Neuropsychopharmacol Biol Psychiatry 2008; 32: 487-491.

25. Pin-Der-Duh $X$. Antioxidant activity of burdock (Arctiumlapalinne). its scavenging effect on free radical and active oxygen. I Am Oil Chem Soc 1998; 75: 455-461.

26. Gordon $\mathrm{MH}$. The mechanism of the antioxidant action in vitro. In: Hudson BJF, editor. Food Antioxidants. London: Elsevier, 1990; p 1-18.

27. Maeda $H$, Akaike T. Nitric oxide and oxygen radicals in infection, inflammation, and cancer. Biochemistry (USSR) 1998; 63: 2408-2416.

28. Halliwell B, Gutteridge JMC. Free radicals in biology and medicine. Oxford: Oxford University Press; 1999.

29. Moskovitz J, Yim MB, Chock PB. Free radicals and disease. Arch Biochem Biophys 2002; 397: 354359. 